\title{
Hipertensão Arterial e Uso de Leflunomida em Artrite Reumatóide
}

\section{Arterial Hypertension and Use of leflunomide in Rheumatoid Arthritis}

\author{
Leonardo M. Schmidt ${ }^{(1)}$, Ana Paula Beckhauser ${ }^{(1)}$, Liz Vallin ${ }^{(1)}$, Marilia B. Silva ${ }^{(2)}$, Thelma L. Skare ${ }^{(2)}$
}

\section{RESUMO}

O aumento de pressão arterial (PA) tem sido descrito em usuários de leflunomida para tratamento de artrite reumatóide (AR). Com o intuito de verificar a existência e a freqüência desse efeito colateral nos pacientes do Hospital Universitário Evangélico de Curitiba (HUEC), procedeu-se ao estudo descrito. Quarenta e um usuários de leflunomida tiveram a aferição da PA feita três vezes antes e três vezes depois do início da leflunomida, utilizando-se o valor médio para cálculos estatísticos. O valor médio de PA sistólica antes do uso da leflunomida foi de $117 \mathrm{mmHg}$ e de $125 \mathrm{~mm}$ depois do tratamento ( $\mathrm{p}=0,0038)$. O valor médio da PA diastólica antes do uso da leflunomida foi de $76 \mathrm{~mm}$ antes e de $80,7 \mathrm{~mm}$ depois do tratamento $(\mathrm{p}=0,0003)$. Concluiu-se que existe aumento tanto na pressão sistólica quanto na diastólica dos usuários de leflunomida.

Palavras-chave: leflunomida, hipertensão arterial, artrite reumatóide.

\section{INTRODUÇÃO}

A leflunomida é um fármaco utilizado para tratamento de doenças reumáticas, principalmente a artrite reumatóide $(\mathrm{AR})^{(1)}$. Exerce ação antiinflamatória e imunomoduladora por meio da inibição de formação do diidroorotato e das tirosinoquinases $^{(2)}$. Seu uso tem sido feito de maneira isolada ou em associação com outros modificadores de doença, no intuito de propiciar bom controle de atividade inflamatória. Todavia, é um medicamento que tem efeitos colaterais que devem ser reconhecidos por aqueles que o usam. Os mais conhecidos são disfunção hepática, lesão de medula óssea, erupções cutâneas, perda de peso, pneumonite intersticial, diarréia e teratogenicidade ${ }^{(2,3)}$. Entre os efeitos indesejados da leflunomida tem sido notado aparecimento ou agravamento da hipertensão arterial (HAS $)^{(4)}$. Embora não muito valorizado, esse é um efeito colateral importante, principalmente quando se observa que pacientes com AR estão sujeitos à doença arteriosclerótica acelerada e às suas

\begin{abstract}
Increase in blood pressure has been noted in patients using leflunomide for rheumatoid arthritis treatment. This study was done to analyze the existence and frequency of blood pressure (BP) changes in our patients using leflunomide. We studied blood pressure in 41 patients before and after using leflunomide. We obtained three blood pressure measurements before and three BP after the introduction of leflunomide with three months interval and used the mean value for study. The mean systolic BP value before leflunomide use was $117 \mathrm{mmHg}$ and $125 \mathrm{~mm} \mathrm{Hg}$ after the use of leflunomide ( $p=0.0038$ ). The mean diastolic pressure was $76 \mathrm{~mm} \mathrm{Hg}$ before leflunomide use and $80.7 \mathrm{~mm} \mathrm{Hg}$ after leflunomide use $(p=0.0003)$. We observed an increased in diastolic and systolic blood pressure in patients using leflunomide.
\end{abstract}

Key words: leflunomide, arterial hypertension, rheumatoid arthritis.

conseqüências cardíacas, renais e cerebrais ${ }^{(5)}$. A presença de HAS pode amplificar essas conseqüências, que contribuem para aumento de morbimortalidade dessa população. Um estudo europeu encontrou prevalência de $3,7 \%$ de casos novos de HAS em seus usuários ${ }^{(6)}$.

Não se sabe como a leflunomida pode causar HAS; a função renal permanece normal e proteinúria não tem sido detectada ${ }^{(4)}$.

No intuito de verificar esse efeito colateral em pacientes locais realizou-se o estudo de 41 usuários de leflunomida para tratamento de AR, sendo cinco homens e 36 mulheres com idade média de 47,6 $\pm 13,6$ anos e tempo médio de duração de doença de $127,7 \pm 70,3$ meses.

Existia história de HAS prévia em oito deles. Foram obtidas no mínimo três medidas de pressão arterial (PA) antes e três medidas depois da introdução do medicamento, com intervalo médio de três meses entre si. A medida da PA foi feita sempre pelo mesmo observador, que se utilizou de esfigmomanômetro aneróide (Heine Gamma 5.0 ${ }^{\circledR}$ ). Todas

Recebido em 15/4/2008. Aprovado, após revisão, em 1/7/2008. Declaramos a inexistência de conflitos de interesse

Serviço de Reumatologia do Hospital Universitário Evangélico de Curitiba (HUEC).

1. Residente do Serviço de Reumatologia do HUEC.

2. Médica do Serviço de Reumatologia do HUEC.

Endereço para correspondência: Thelma L. Skare, Rua João Alencar Guimarães, 796, 80310-420, Curitiba, PR, e-mail: tskare@onda.com.br 
as medidas foram feitas com os pacientes sentados, pela manhã (entre 8 e 10 horas), no braço esquerdo e após 15 minutos de repouso. Para o cálculo considerou-se o valor médio antes e depois do uso. Nenhum dos pacientes usou dose inicial de $100 \mathrm{mg}$, sendo todos introduzidos em 20 $\mathrm{mg} /$ dia. Em nenhum dos pacientes houve alteração no uso de antiinflamatórios e os valores de alteração máxima no uso de prednisona foram de $\pm 5 \mathrm{mg} /$ dia.

Os resultados mostraram que a média da PA sistólica desses pacientes foi de $117,4 \pm 19,1 \mathrm{mmHg}$ antes do uso da leflunomida e de $125,4 \pm 25,25 \mathrm{mmHg}$ após $(\mathrm{p}=0,0038$; teste $\mathrm{t}$ ). Figura 1: A média da PA diastólica foi 76,3 $\pm 11,2 \mathrm{mmHg}$ antes e de 80,8 $\pm 12,0 \mathrm{mmHg}$ após ( $\mathrm{p}=0,0003$; teste $\mathrm{t}$ de Student). Figura 2: Em seis pacientes houve necessidade de introdução ou aumento da medicação anti-hipertensiva. A diferença de PA sistólica observada nestes pacientes foi de -27 a $+49 \mathrm{mmHg}$ (média de $8,0 \pm 16,7$ ) e para a diastólica foi de -13 a +24 mmHg (média de $4,4 \pm 7,2$ ).



Figura 1 - Valores de pressão arterial sistólica antes e depois do uso de leflunomida.

\section{REFERÊNCIAS}

1. Ek 1, Tam LS, Tomlinson B: Leflunomide in the treatment of rheumatoid arthritis. Clin Ther 26: 447-59, 2004.

2. Alldred A, Emery B: Leflunomide: a novel DMARD for the treatment of rheumatoid arthritis. Expert Opin Pharmacother 2: 125-37, 2001.

3. Kremer JM: What I would like do know about leflunomide. J Rheumatol 31: 1029-30, 2004.
No presente estudo, constatou-se o aumento médio tanto da PA sistólica quanto da diastólica com a introdução do leflunomida. Todavia, como as diferentes medidas foram feitas com o intervalo de três meses entre si, a constatação de nível pressórico elevado levou à introdução ou à modificação do tratamento anti-hipertensivo em seis dos pacientes. É possível que a média da PA fosse mais elevada se esses seis pacientes não tivessem sido medicados com anti-hipertensivos entre as aferições antes e depois do tratamento.

Outro aspecto a ser notado é que nem todos os pacientes apresentaram aumento nos níveis pressóricos. Isso talvez possa ser explicado se existirem fatores idiossincráticos envolvidos no mecanismo da hipertensão, fazendo que apenas parte da população estudada tenha apresentado aumento.

O acompanhamento da PA de pacientes usuários de leflunomida é fundamental para se detectar possíveis aumentos e impedir as suas conseqüências sobre o paciente.

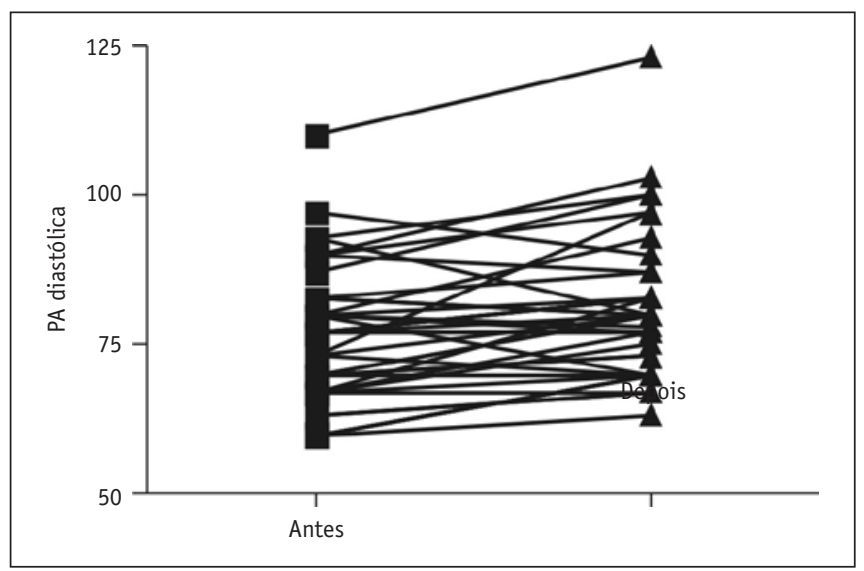

Figura 2 - Valores da pressão arterial diastólica antes e depois do uso de leflunomida.

4. Rosman B, Praprotnik S, Logas D, et al.: Leflunomide and hypertension. Ann Rheum Dis 61: 567-9, 2002.

5. Manzi S, Wasko MCM: Inflammation mediated rheumatic diseases and atherosclerosis. Ann Rheum Dis 59: 321-5, 2000 .

6. Smolen JS, Kalden JR, Rozman B, et al.: Efficacy and safety of leflunomide compared to placebo and sulfasalazine and active rheumatoid arthritis. A double blind randomized multicenter study. Lancet 353: 259-66, 1999. 